\title{
Agricultural Products Quality and Safety Monitoring System Research Based On Supply Chain
}

\author{
Tingting Tang ${ }^{1, a}$, Min Wang ${ }^{1, b}$, Yu Zhang ${ }^{1, \mathrm{c}}$, Yuting Yang ${ }^{1, \mathrm{~d}}$, Jinling $\mathrm{Li}^{1, \mathrm{e}}$ and \\ Jianming Sun ${ }^{1, f^{*}}$ \\ ${ }^{1}$ Harbin University of Commerce, China

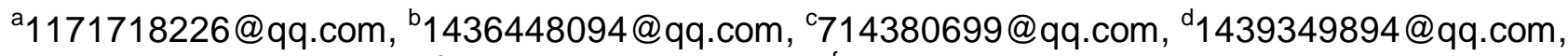 \\ e3266028193@qq.com, 'sjm@hrbcu.edu.cn
}

Keywords: Agricultural product; The quality and safety; The supply chain; Risk analysis; Monitoring system

\begin{abstract}
Agricultural Products are necessity of people's daily life. The quality and safety of agricultural products is related to human health even life safety, with concern extent increasing. The quality and safety of agricultural products exists in the food supply chain from "farmland" to "dining table", including production, processing, logistics and sales. Therefore, the monitoring of food quality and safety will run through the food supply chain. At present, domestic and foreign research on food supply chain security and agricultural product quality and safety monitoring system is also increasing, but never formed a unified, quantitative integration system.
\end{abstract}

\section{Introduction}

From ancient times to the present, China is a large agricultural country, with a large population, a large demand for agricultural products, and agricultural products are necessities of life. With the development of science and technology, the agricultural products industry has also developed unprecedentedly. A series of research and development have made the new agricultural products which meet the needs of the market come into being. The development of a wide range of functional agricultural products has brought about economic growth for the agricultural products industry. However, "everything has two sides, although the development in our country, but the quality and safety of agricultural products is the frequent occurrence of accidents, one after another, many more merchants to violate the moral constraint is added to the harmful substances in the agricultural products, and even endanger people's lives.

\section{Research Status Quo}

Status of Foreign Research. Foreign scholars began to study the quality and safety of agricultural product from the beginning of the 20th century. Upton Sinclair was one of the earliest scholars of food safety, and in 1906, the book "The Jungle" described in detail the main factors affecting the quality of meat in Chicago. Professor of the University of Wisconsin in 1908 put forward the concept of organic food, describes the application of human and animal manure, rice straw, river mud and other organic fertilizer benefits [1]. British microbiologist Howard through research, that the use of organic fertilizer can create a good soil fungal activity environment, and excessive use of fertilizers inhibit fungal activity, affecting soil quality. In the 1970s, American soil scientist Albrecht proposed the concept of eco-food. British scholar Elkington published the "Green Consumption Research Guide" [2], advocating the people to green consumption. American economist David (1996) studied the relationship between the consumption demand of ordinary agricultural products and the consumption demand of safe agricultural products, expounded the factors that affect the quality and safety of agricultural products and the willingness to pay for the safety of agricultural products [3]. British economist Marsden (1999) studied the impact of consumer preferences on producers' products and discussed the quality and safety preferences of consumers [4]. Antle (2007), Caswell (1992) and other information on agricultural safety 
is divided into asymmetric incomplete information and symmetrical incomplete information, agricultural products will be divided into search, experience and credit [5]. Stiglitz (1989) argues that consumers with the ability to access information and deal with information acquire quality and safety of agricultural products in markets with complete information on competitive markets or incomplete information but with high corporate credibility [6].

Status of Domestic Research. China's agricultural product quality and safety monitoring system started late, which is determined by the stage of agricultural production in China. Before the 1990s, the focus of agricultural production in China was to increase the output of agricultural products. In recent years, frequent agricultural product safety and safety accidents have made the research on the quality and safety management system of agricultural products pay more and more attention. (2002) pointed out that a kind of agricultural products from the farm to the table, to go through the production, processing, circulation and many other aspects of agricultural products supply system tends to be complicated and internationalized. The chain of agricultural products supply more and more long, more and more links, the scope of more and more widely, the higher the probability of occurrence of agricultural product quality and safety risks. Li et al. (2005) argue that the quality and safety of agricultural products can be improved through the introduction of Total Quality Management (TQM) and the basic principles and methods of implementation are proposed. Wang Xiuqing and so on from the information asymmetry theory, the study of China's agricultural products on the market quality signal problem, proposed from the edible agricultural products industry chain as a whole, set up a national agriculture and food sector unified institutions, and ultimately promote the quality of agricultural products safety and effective To ensure food safety. Zhou et al. (2002) discussed the issue of information asymmetry and government regulation mechanism in the management of quality and safety of edible agricultural products with the same theory as the background. It was pointed out that the government could promote the quality and safety management of agricultural products through market access, inspection supervision and safety identification system.

\section{Quality and Safety Risk Analysis Method}

Risk analysis should be the development needs of aerospace, finance, insurance, telecommunications, military intelligence and other industries widely used. The aerospace food industry first used risk analysis as the beginning of a risk analysis of the food industry. The approach was mainly due to two aspects, namely, the problems of quality safety and the preventive measures that can be taken.

Risk analysis applied to food quality and safety generally experienced the following processes, food safety assessment, the application of modern biotechnology, risk analysis. Early 1950: Hygienic standards were developed for food safety assessments based on acute and chronic toxicity tests, taking into account human daily acceptable intake (ADI). The concept of the zero threshold of carcinogens was presented in 1960 by the Delaney amendment in the United States, whose core idea was to eliminate the need to add harmful chemical substances within the food. In the late 1970s, the concept of a zero threshold was changed when some unavoidable or non-preventable carcinogenic substances were found without substitutes, and the result of the evolution was "acceptable risk", and there was a risk Evaluation.

Global food quality and safety issues and the resulting safety incidents have also contributed to the widespread use of risk analysis. Such as the occurrence of British mad cow disease between 1996 and 2005, avian flu in Hong Kong, swine encephalitis in Southeast Asia, Belgian dioxin storm, Listeria monocytogenes, Asian exports of shrimp products with chloramphenicol residues and other events The Food safety accidents in the United States as well as developed countries as high as 81 million cases. Therefore, by the end of 1980, the true sense of food safety risk analysis was fully implemented. At the same time, in the early 1990s, at the joint meeting of the Food and Agriculture Organization of the United Nations, the World Health Organization and the International Codex Alimentarius Commission, the use of risk analysis techniques to assess food safety hazards was formally introduced. The application of the risk analysis methodology was subsequently presented at the meeting of the International Codex Alimentarius Commission. At this point, the food safety risk analysis method based 
on the relevant resolutions and regulations has become the technical basis and scientific principle of the Codex standard.

Risk analysis methods include the following (as shown in Table 1):

Table 1 Risk analysis methods

\begin{tabular}{|c|c|c|c|}
\hline Classification & & Brief steps & Applicable scope \\
\hline $\begin{array}{l}\text { Risk } \\
\text { comprehensiv } \\
\text { e evaluation } \\
\text { method }\end{array}$ & & $\begin{array}{c}\text { Investigate expert opinion } \rightarrow \text { Get the } \\
\text { weight and probability of risk factors } \rightarrow \\
\text { Get the overall risk of the project }\end{array}$ & $\begin{array}{l}\text { The whole process of } \\
\text { risk analysis }\end{array}$ \\
\hline $\begin{array}{c}\text { Expert } \\
\text { investigation }\end{array}$ & & $\begin{array}{l}\text { Expert subjective judgment } \rightarrow \text { identify } \\
\text { potential risks of the project }\end{array}$ & $\begin{array}{l}\text { The whole process of } \\
\text { risk analysis }\end{array}$ \\
\hline \multirow{2}{*}{$\begin{array}{l}\text { Risk } \\
\text { probability } \\
\text { estimation }\end{array}$} & $\begin{array}{l}\text { Objective } \\
\text { probability } \\
\text { estimation }\end{array}$ & $\begin{array}{l}\text { Objective data } \rightarrow \text { calculate the objective } \\
\text { probability } \rightarrow \text { the project risk estimates }\end{array}$ & $\begin{array}{l}\text { Completely } \\
\text { repeatable events }\end{array}$ \\
\hline & $\begin{array}{l}\text { Subjective } \\
\text { probability } \\
\text { estimation }\end{array}$ & $\begin{array}{l}\text { Expert subjective inference probability } \\
\quad \rightarrow \text { project risk estimation }\end{array}$ & $\begin{array}{l}\text { If the effective } \\
\text { statistics are } \\
\text { insufficient or are not } \\
\text { likely to be tested }\end{array}$ \\
\hline Risk analysis & & $\begin{array}{l}\text { Through the analysis of the subsystem } \\
\text { and then grasp the subsystems of the } \\
\text { entire system features }\end{array}$ & $\begin{array}{l}\text { The whole process of } \\
\text { risk analysis }\end{array}$ \\
\hline $\begin{array}{l}\text { Probability } \\
\text { tree analysis }\end{array}$ & & $\begin{array}{l}\text { Assuming the independence of the risk } \\
\text { variable } \rightarrow \text { Assignment of the variable } \rightarrow \\
\text { Calculate the evaluation index and } \\
\text { probability of each combination } \rightarrow \text { Make } \\
\text { the correlation calculation } \rightarrow \text { Draw the } \\
\text { cumulative probability curve }\end{array}$ & $\begin{array}{c}\text { The whole process of } \\
\text { risk analysis }\end{array}$ \\
\hline $\begin{array}{l}\text { Analytic } \\
\text { Hierarchy } \\
\text { Process }\end{array}$ & & $\begin{array}{c}\text { Comparison of the same level of risk } \\
\text { factors important degree } \rightarrow \text { listed } \\
\text { judgment matrix } \rightarrow \text { probability } \\
\text { distribution }\end{array}$ & $\begin{array}{l}\text { The whole process of } \\
\text { risk analysis }\end{array}$ \\
\hline
\end{tabular}

Identification and Selection of Quality and Safety Risk Factors in Agricultural Supply Chain. People to food for the day, China's large population, the growing demand for food. In 2012, the national grain output reached 58.957 million tons, an increase of 18.37 million tons over the previous year, an increase of 3.2 percent; 2013 national total grain output reached 601.93 million tons, an increase of 2.1 percent; 2014 national grain output 607.02 million tons, an increase of $0.8 \%$; 2015 national grain output 62.143 million tons, an increase of $2.4 \%$. Many people need a lot of food, so the quality and safety of agricultural products is also essential. In recent years, China's major production of several agricultural products (as shown in Table 2)

Table 2 China's agricultural production in recent years

\begin{tabular}{|c|c|c|c|c|c|}
\hline Category & 2011 year & 2012 year & 2013 year & 2014 year & 2015 year \\
\hline Paddy & 20100.09 & 20423.59 & 20361.22 & 20650.74 & 20822.52 \\
\hline Wheat & 11740.09 & 12102.36 & 12192.64 & 12620.84 & 13018.52 \\
\hline Corn & 19278.11 & 20561.41 & 21848.90 & 21564.63 & 22463.16 \\
\hline Sorghum & 205.09 & 255.55 & 289.20 & 288.50 & - \\
\hline
\end{tabular}


But in recent years the frequent occurrence of various accidents, not only caused a huge economic losses, but also harm the safety of consumers. The occurrence of the accident is largely due to the shortage of quality risk management of agricultural product supply chain. Therefore, we should strengthen the research on the quality and safety risk of agricultural products. The quality and safety of agricultural products involves the production, processing, circulation and sale of agricultural products to the table and other chain of the different links. Therefore, this is based on agricultural supply chain analysis of agricultural product quality and safety risk factors, with a view to the future of relevant research to provide a reference.

Identification of Risk Factors. Through the analysis and analysis of related literature, the questionnaire was designed and the quality and safety risk factors were obtained. Before the official issue of the questionnaire, the first consultation and consultation of the relevant personnel and experts, and field interviews and case studies, the questionnaire risk factors to improve and finally get the risk factor variable table, shown in Table 3.

Table 3 Agricultural product quality and safety risk factors variable table

\begin{tabular}{|c|c|}
\hline Numbering & Risk variable \\
\hline X1 & Input category \\
\hline X2 & Pesticide ingredients \\
\hline X3 & Origin environment \\
\hline X4 & Planting pattern \\
\hline X5 & Farmer 's moral level \\
\hline X6 & Differentiated pricing \\
\hline X7 & Production technology \\
\hline X8 & Production equipment status \\
\hline X9 & Cleaning disinfection \\
\hline X10 & Processing environment \\
\hline X11 & Sales Forecast \\
\hline X12 & Storage and transportation \\
\hline
\end{tabular}

Design of the Questionnaire. The questionnaire is divided into two parts: First, fill the basic information (work environment, business experience, etc.); Second, agricultural product quality and safety risk factors related to the problem. The questionnaire involved a total of 12 risk factors, using the Likert-type five-point scale, 1-5 on behalf of the impact from the lowest to the highest minimum, smaller, medium, large and great. The survey respondents include the main consumer groups, the staff engaged in the work related to agricultural products and the relevant research experts, the questionnaire delivery methods, including on-site delivery, letter sent, e-mail sent. A total of 100 questionnaires were issued and 70 valid questionnaires were collected.

Sample Reliability Test. Due to the difference between the respondents' understanding of the questionnaire, the questionnaire needs to be tested for reliability. The reliability of 70 samples was tested by SPSS 19.0, and the degree of consistency of 13 risk factors was examined. Using the Cronbaeh alpha coefficient calculation method, the results are shown in Table 4.

Table 4 Reliability measurement

\begin{tabular}{|l|l|}
\hline Cronbaeh's Alpha & Number of items \\
\hline .822 & 12 \\
\hline
\end{tabular}

As can be seen from Table 4, the alpha coefficient of the original survey questionnaire is 0.822 , greater than 0.8 . Indicating that the survey sample data reliability is good, to meet the needs of this statistical analysis. 
Factor Analysis. Statistical analysis of the questionnaire, using factor analysis method. Factor analysis is the combination and synthesis of many overlapping information in real life, which changes the original multiple variables and indexes into less comprehensive variables and comprehensive indexes, which is beneficial to the analysis and judgment.

This paper uses the SPSS software through the method of documentation, questionnaire and factor analysis, analysis of the quality and safety of key risk factors (common factors), and each factor influence coefficient for agricultural product quality safety risk assessment and management to provide reference.

\section{Analysis of Quality Safety Risk Factors Based on Factor Analysis}

In this paper, SPSS19.0 is used to analyze the data. Firstly, KMO and Bartlett test, see if the factor analysis and further analysis; then using principal component analysis, according to the interpretation of the total variance and gravel map extraction common factor; the maximum variance method of factor rotation, the rotation matrix components, to explain the common factor; according to the component score coefficient matrix, get the numerical public factor finally, the comprehensive score of the quality and safety risk value for risk control and management.

KMO and Bartlett Tests. The KMO and Bartlett tests should also be tested using SPSS19.0, as shown in table 5. The result of Bartlett test can determine whether the data from the general multivariate normal distribution, from table 5 we can see that the Sig value is 0 , lower than the significance level 0.05 , the data from normal distributions, 13 variables are not independent, for further analysis.

Table $5 \mathrm{KMO}$ and Bartlett tests

\begin{tabular}{|c|c|c|}
\hline \multicolumn{2}{|c|}{ Kaiser-Meyer-Olkin of sampling sufficiency } & .619 \\
\hline \multirow{3}{*}{$\begin{array}{c}\text { Sphericity test of } \\
\text { Bartlett }\end{array}$} & $\begin{array}{c}\text { Approximate chi } \\
\text { square }\end{array}$ & 417. \\
\cline { 2 - 3 } & $\mathrm{df}$ & 726 \\
\cline { 2 - 3 } & Sig & .000 \\
\hline
\end{tabular}

Extracting Common Factors. The eigenvalues of the correlation matrix of the 12 variables are obtained, and the total variance and the broken stone plots are given, as shown in Table 6 and fig. 1.

Table 6 Explains the total variance

\begin{tabular}{|c|c|c|c|c|c|c|c|c|c|}
\hline \multirow{2}{*}{ component } & \multicolumn{3}{|c|}{ Initial eigenvalue } & \multicolumn{3}{|c|}{ Extract sum of squares load } & \multicolumn{3}{|c|}{$\begin{array}{l}\text { Rotation sum of squares } \\
\text { loading }\end{array}$} \\
\hline & Total & $\begin{array}{l}\% \\
\text { variance }\end{array}$ & Cumulative \% & Total & $\begin{array}{l}\% \\
\text { variance }\end{array}$ & Cumulative \% & Total & $\begin{array}{l}\% \\
\text { variance }\end{array}$ & Cumulative\% \\
\hline 1 & 4.754 & 35.232 & 35.232 & 4.258 & 35.232 & 35.232 & $\begin{array}{r}40 \\
321 \\
\end{array}$ & 31.201 & 31.025 \\
\hline 2 & 2.603 & 16.023 & 50.274 & 2.301 & 17.201 & 50.231 & $\begin{array}{l}1.7 \\
20\end{array}$ & 13.528 & 56.231 \\
\hline 3 & 1.452 & 12.258 & 62.314 & 1.441 & 13.021 & 64.320 & $\begin{array}{l}1.6 \\
33\end{array}$ & 12.365 & 68.213 \\
\hline 4 & 1.235 & 10.102 & 70.394 & 1.362 & 9.267 & 70.213 & $\begin{array}{l}1.3 \\
54\end{array}$ & 10.954 & 67.201 \\
\hline 5 & 1.032 & 7.365 & 77.201 & 1.022 & 7.641 & 78.732 & $\begin{array}{l}1.3 \\
20\end{array}$ & 10.320 & 77.321 \\
\hline 6 & .567 & 6.235 & 84.035 & & & & & & \\
\hline 7 & .536 & 5.214 & 88.365 & & & & & & \\
\hline 8 & .391 & 3.541 & 91.301 & & & & & & \\
\hline 9 & .326 & 2.367 & 94.308 & & & & & & \\
\hline 10 & .297 & 1.638 & 95.447 & & & & & & \\
\hline 11 & .236 & 1.305 & 97.025 & & & & & & \\
\hline 12 & .170 & .578 & 100.000 & & & & & & \\
\hline
\end{tabular}


From table 6, the initial feature value column shows the first 5 factors with eigenvalues greater than 1, so SPSS chose the top 5 principal components; the first 5 factors of the cumulative variance contribution rate of $80.98 \%$, basically can be summed up in the original 12 variables of information. Thus, the first 5 factors can basically replace the original variables, and basically reflect the essential information of the sample.

The factor macadam (Fig. 1) shows that the eigenvalues of the first 5 factors are greater than 1, while the other factors are all less than 1. Therefore, the first 5 factors are chosen as the common factors. In this way, the original 13 quality safety risk factor variables are extracted into 5 common factors, which play a role in reducing dimensionality.

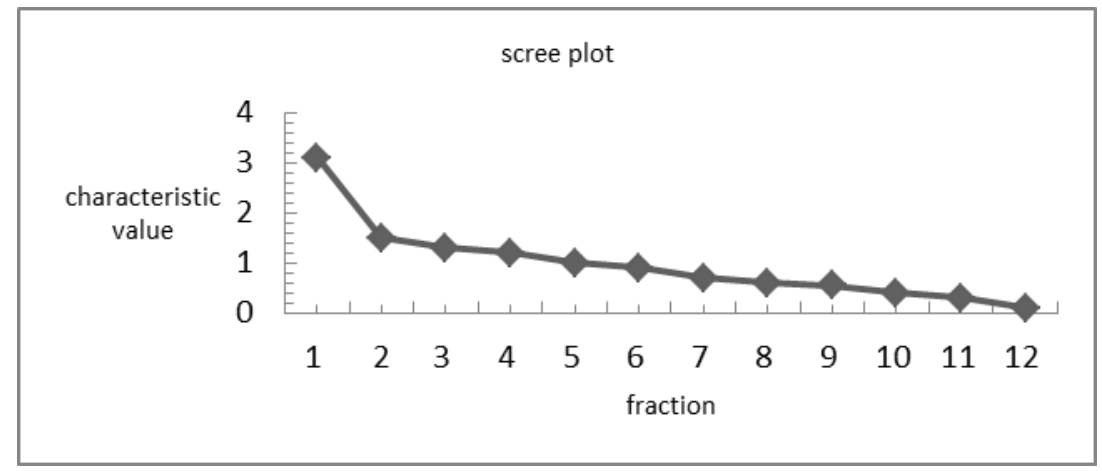

Figure 1. factor lithotripsy

Factor Load Analysis. Make each variable have a relatively high load on the 5 common factors, and use the maximum variance method for factor rotation to obtain the rotation component matrix, as shown in table 7.

Table 7 shows the load on the 12 variables of the 5 common factors, and 12 variables can be categorized and summarized.

Table 7 Rotation component matrix

\begin{tabular}{|c|c|c|c|c|c|}
\hline & \multicolumn{5}{|c|}{ component } \\
\cline { 2 - 6 } & 1 & 2 & 3 & 4 & 5 \\
\hline Production technology X7 & .864 & .011 & -.031 & -.002 & .151 \\
\hline Discrimination pricing X6 & .802 & -.114 & -.050 & -.017 & .115 \\
\hline Production equipment status X8 & .781 & -.045 & -.101 & .325 & .084 \\
\hline Cleaning and disinfection X9 & .733 & .260 & .010 & .050 & .216 \\
\hline Habitat environment X3 & .687 & -.151 & .190 & -.124 & -.321 \\
\hline Sales forecast X11 & .677 & .456 & -.120 & -.055 & .104 \\
\hline Cropping pattern X4 & .624 & .601 & .365 & .008 & -.071 \\
\hline Machining environment X10 & -.030 & .853 & .027 & -.006 & -.013 \\
\hline Pesticide composition X2 & -.007 & -.066 & .850 & .035 & .040 \\
\hline Storage and transportation X12 & -.051 & .004 & -.052 & .948 & -.074 \\
\hline Input breed class X1 & .461 & -.085 & .233 & .568 & .503 \\
\hline Farmers' moral level X5 & .138 & -.012 & -.305 & -.052 & .954 \\
\hline
\end{tabular}


Common Factor Naming. According to the rotation component matrix table, the 5 categories of factor groups are summarized, named and explained, and the main factors affecting the decision risk are generalized. Table 8 .

Table 8 Common factor naming table

\begin{tabular}{|c|c|c|}
\hline $\begin{array}{c}\text { Common factor } \\
\text { number }\end{array}$ & Risk factor & Common factor naming \\
\hline F1 & $\mathrm{X} 6, \mathrm{X} 7, \mathrm{X} 8$ & Hardware risk \\
\hline F2 & $\mathrm{X} 9$ & Elimination risk \\
\hline F3 & $\mathrm{X} 4$ & Planting risk \\
\hline F4 & $\mathrm{X} 2, \mathrm{X} 3, \mathrm{X} 5, \mathrm{X} 10, \mathrm{X} 11, \mathrm{X} 12$ & External environment risk \\
\hline F5 & $\mathrm{X} 1$ & Original risk \\
\hline
\end{tabular}

Factor Analysis Score. Thus, the score of the 5 common factors can be calculated, and the component score coefficient matrix can be obtained by using SPSS19.0, as shown in table 9.

Table 9 Component score coefficient matrix

\begin{tabular}{|c|c|c|c|c|c|}
\hline & \multicolumn{5}{|c|}{ component } \\
\cline { 2 - 6 } & 1 & 2 & 3 & 4 & 5 \\
\hline Types of inputs & .035 & -.087 & .156 & .325 & .302 \\
\hline Pesticide composition & -.034 & -.196 & .624 & -.017 & .056 \\
\hline Habitat environment & -.035 & -.002 & .014 & -.164 & .754 \\
\hline Cropping pattern & .245 & -.200 & .144 & -.105 & -.321 \\
\hline Farmers moral level & .124 & .201 & .154 & .002 & -.103 \\
\hline Storage and transportation & -.056 & .233 & .354 & -.014 & -.027 \\
\hline Differential pricing & .233 & -.147 & -.045 & -.074 & -.005 \\
\hline Production technology & .214 & -.054 & -.044 & -.065 & .024 \\
\hline Production equipment status & .187 & -.054 & -.087 & .200 & -.060 \\
\hline Cleaning and disinfection & .160 & .114 & .006 & -.13 & .087 \\
\hline Machining environment & -.087 & .546 & -.130 & .054 & .014 \\
\hline Sales forecast & .145 & .236 & -.153 & -.065 & .017 \\
\hline Storage and transportation & -.056 & .233 & .354 & -.014 & -.027 \\
\hline
\end{tabular}

According to the factor score coefficient matrix, the score of 5 common factors can be obtained, and the function is calculated as follows:

$$
\begin{aligned}
& \mathrm{f} 1=0.035 \times 1-0.034 \times 2+\ldots+0.056 \times 12 \\
& \mathrm{f} 2=-0.087 \times 1-0.196 \times 2+\ldots+0.233 \times 12 \\
& \quad \ldots \\
& \mathrm{f} 5=0.302 \times 1+0.056 \times 2+\ldots-0.027 \times 12
\end{aligned}
$$

Each risk factor has different effects on the quality and safety of agricultural products. It can be evaluated according to the extent of its performance, and then the scores of 5 common factors are calculated according to the above functions. According to the magnitude of the public factor score, the size of the quality and safety marketing can be evaluated.

According to table 6 , the percentage contribution rate of variance is calculated by using the sum of squares of rotation, as in formula: 
Factor transformation weights $=($ variance ratio of common factor $\mathrm{X} 100 / 78.737) / 100$

For example, the common factor 1 transforms the weight $=(31.201 * 100 / 78.737) / 100=0.3963$, so that the weights of the 5 common factors can be constructed, and the principal component synthesis model can be constructed, and the model expressions are as follows:

$$
\mathrm{Z}=0.3963 \mathrm{~F} 10.1718 \mathrm{~F} 20.1570 \mathrm{~F} 30.1391 \mathrm{~F} 40.1311 \mathrm{~F} 5
$$

According to the situation of risk factors, the score of 5 common factors is substituted into the above model expression, and then the value of agricultural product quality safety risk can be obtained. So, according to the risk values of risk level, according to the risk decision making corresponding risk control measures, risk management, to improve the quality and safety of agricultural products, protect the personal safety of consumers.

Due to the existence of quality and safety risk factors of uncertainty of agricultural products supply chain, then the formation of relevant prevention mechanisms, not only to strengthen the supply chain management of internal control, but also to form the external network, the construction quality and safety of agricultural products and internal and external supervision system through the information tracking system to achieve better. The supervision of the quality and safety of agricultural products is divided into two parts, namely, the control of the quality of agricultural products within the agricultural enterprises and the external supervision of the government, the public and so on. Internal control refers to the interrelated control activities which are coordinated and carried out by all levels of management in order to ensure the realization of enterprise organizational goals. The HACCP system is officially recommended as a general method of controlling the quality and safety of foods, including dairy products. However, the HACCP system is currently only used in the production process of food. In order to effectively control the quality and safety of agricultural products, in the construction of "basic management mode of the supply chain of agricultural products, suggest that the HACCP system can be used in the whole supply chain, this is to ensure that the ideas and methods of internal control. Therefore, form the perspective of internal control, somebody is know that how to apply the HACCP system to the whole supply chain, in order to ensure the quality and safety of agricultural products.

\section{Monitoring System of Agricultural Product Quality and Safety Based on Supply Chain}

Building an integrated supply chain is the basis for ensuring the quality and safety of agricultural products. Therefore, the monitoring logic of the quality and safety of agricultural products should be put forward and implemented based on the supply chain.

The monitoring system of agricultural product quality safety mainly consists of three parts, supply chain, internal control and external supervision. The core of the system is the supply chain of agricultural products, and all the subjects are carried out around the supply chain. On this basis, the agricultural product production enterprises as the core strength to lateral control with HACCP system of quality and safety of the internal supply chain, and mainly by the government and other subjects have supplemented by regulation of various longitudinal related behavior from outside the supply chain. The operation of such a Criss Cross regulatory system can guarantee the quality and safety of agricultural products in all directions, and ensure that consumers enjoy safe and secure agricultural products.

\section{Summary}

With the rapid development of the agricultural products industry, the quality and safety of agricultural products has attracted more and more attention from all walks of life. How to supervise and manage the quality and safety of agricultural products has become an urgent social problem. The backward quality and safety monitoring technology, imperfect quality and safety supervision system have seriously restricted the healthy development of food safety in china. All aspects of the quality and safety of agricultural products to the whole supply chain, only monitoring from within a link or agricultural enterprise is not able to do comprehensive protection of agricultural products quality and safety, we must proceed from the angle of the supply chain of agricultural products, analysis of how to construct the management model of agricultural products supply chain and overcome its limitations. Establish 
agricultural product quality and safety supervision system to ensure the quality and safety of agricultural products.

Based on the analysis of risk factors on the quality and safety of agricultural products, the agricultural products supply chain, with the help of HACCP horizontal control system of quality and safety of the internal supply chain, and mainly by the government and other subjects have supplemented by regulation of various longitudinal related behavior from outside the supply chain. To monitor and control the quality and safety of agricultural products, a monitoring system for the quality and safety of agricultural products has been established. The main research contents and innovations are as follows:

- the concept of the basic theory of the quality and safety of food is introduced, and the related knowledge of the management of the quality and safety of agricultural products is introduced in detail.

- the risk factors of quality and safety of agricultural products supply chain is analyzed and studied, the agricultural products supply chain is divided into raw materials, provide production and processing, circulation and sales of four links, establish the quality and safety of agricultural products monitoring system. On the basis of constructing the supply chain management model of agricultural products, the principle of HACCP system is applied to the internal monitoring of the supply chain of agricultural products, which can fundamentally protect the quality of agricultural products and provide more reference for external monitoring.

This paper stands in the food supervision and management perspective, through the analysis of risk factors with the necessity of supervision, the formation of the quality and safety of agricultural products monitoring system based on supply chain, enrich and develop the basic theory of the safety monitoring of the quality of agricultural products, but also provide valuable suggestions for the improvement of food safety supervision system Chinese.

From the author's own weak basic theory knowledge, research efforts to make the contents there are not enough, as follows: the practical research to study of all aspects of the supply chain of agricultural products is not thorough enough, the quality and safety of agricultural products monitoring logic. Limited by the ability of individuals, there are many inadequacies in the article. Please be criticized by experts.

\section{Acknowledgement}

This work was supported by Harbin University of Commerce young creative talents Support project (Grant Nos.2016QN050), and Harbin University of Commerce Teaching reform and teaching research project(Grant Nos. HSDJY19). And this is the national program for innovation and entrepreneurship training program for Harbin University of Commerce students (Grant Nos.201610240048).

\section{References}

[1] Tanner, C, B, Simonson, R, W. Franklin, Hiram, King-Pioneer, [EB/OL].http://www.soils.wise.edu/soils/people/poets/fh_king.htm./2007-03-26., Scientist

[2] Elkington J, Hailes J. green consumer guide [M]

[3] Variyam, JN, JamesB, David, S.Modeling, Nutrition, Knowledge, Attitudes, and, Diet-Disease, Awareness:The, Case, of, Dietary,Fiber[J].Statistics, in, Medicine, 15:23-35,...

[4] Marsden T, Flynn A, Harrison M. Consuming interests: the social provision of food choice (consumption \&space)[M].London:UCL, 1999.

[5] Antle J M. Benefits and costs of food safety regulation.

[6] Grossman S J. The informational role of warranties and private disclosure about product quality [J]. J Law Econ, 1981,24(3):461-483.

[7]Fan Xiaojian, the status quo and main tasks of quality and safety of agricultural products in China [J], agricultural quality standards,2004(3):4-6.

[8] Zhou Yingheng, research on the application of agricultural modernization in the food safety and quality assurance of the information traceability system Geng gaba [J], 2002(6):451-454. 
[9] Li Yaotian, Richardson, Total quality management of agricultural products and industrialization of agriculture[J], Quality of China,2011(11):22-24.

[10] Wang Xiuqing, Sun Yunfeng. Quality signals in China's food market [J]. China's rural economy,2002(5):27-53. 